\title{
Konya Kapalı Havzası Orman, Mera ve Tarım Alanlarının Değerlendirilmesi
}

\author{
Ayhan ATEŞOĞLU ${ }^{1 *}$, Talha Berk ARIKAN ${ }^{1}$, Saffet YILDIZ $^{1}$ \\ Bartın Üniversitesi, Orman Fakültesi, Orman Mühendisliği Bölümü,74100, BARTIN
}

Öz

Çalışma, Konya Kapalı Havza (KKH)'sının $\left(\sim 50000 \mathrm{~km}^{2}\right)$ güncel arazi örtü/kullanım sınıflarının tespiti, her bir sınıfa ait durum tespiti, kuraklık sınıflarına göre arazi örtü/kullanım sınıflarının durumu, arazi değişimlerinin yönü ve eğilimlerinin belirlenmesine yönelik veri üretmek amacıyla gerçekleştirilmiştir. Çalışmada kullanılan yöntem amaca uygun arazi izleme ve değerlendirme amaçlı Collect Earth yöntemidir. Açık kaynaklı ve ücretsiz olan Collect Earth yazılımında görsel ve grafik değerlendirmeler için yüksek ve orta çözünürlüklü uydu görüntü verileri (Google Earth, Bing maps, Yandex maps, Google Earth Engine vb. üzerinden) entegre olarak kullanılmıştır. SAIKU isimli istatistik programı yardımıyla veri analizi ve rakamsal sonuç verilerine ulaşılmıştır. Çalışma sonucunda, 2018 yılı itibari ile arazi kullanım dağılımları; Tarım \%45,77, Orman \%5,18, Mera \%20,86, Diğer $\% 21,70, \mathrm{Su} \% 4,03$ ve Yerleşim \%2,46 olarak tespit edilmiştir. Kuraklık sınıflarına göre arazi kullanım dağııımları incelendiğinde arazi kullanımlarının \%53,31 "yarı kurak" sınıfta yer almaktadır. Yarı kurak sınıf içerisinde ise en büyük arazi kullanım sınıfı (1,24 milyon ha) tarım sınıfıdır. Konya kapalı havza içerindeki toplam tarım alanlarının \%35,98'i sulanan tarım alanlarıdır. KKH'nın \%9,40'ı ağaçla kaplı alanlar içerisinde yer almaktadır. Arazi kullanım değişimleri incelendiğinde, 2000-2018 yılları arasında en büyük artış 20521 ha ile tarım sınıfında yaşanmıştır. Genel olarak değişim yönü 'diğer' arazi sınıflarından 'tarım' arazi sınıfına doğru gerçekleşmiştir. Gerçekleştirilen çalışma gerek tematik harita gerekse rakamsal verileri ile KKH için yapılacak altlıklara güncel veri sağlayacaktır.

Anahtar Kelimeler: Konya Kapalı Havzası, Collect Earth, arazi örtü/kullanım sınıfları, izleme değerlendirme.

\section{Assessment of Forest, Grassland and Agricultural Land Use in Konya Basin}

\begin{abstract}
This study was carried out to determine the class of the land use/cover classes, check and appraisal of land use/cover classes, land use/cover classes according to aridity zones, land use/cover change/conversion (20002018) in Konya Basin. Collect Earth, a multipurpose land monitoring software, was used in the study. High and middle resolution image data (with use Google Earth, Bing Maps, Yandex Maps, Google Earth Engine etc.) in Collect Earth software, open source and free, uses for data analysis and together for visual and graphics assessment. Data analysis and numerical results can be obtained by using the SAIKU. At the end of the study, Distribution of land use classes is detect as of 2018; 45.77\% Cropland, 5.18\% Forest land, 20.86\% Grassland, $21.70 \%$ Other land, $4.03 \%$ Wetlands, $2.46 \%$ Settlements. According to aridity zones $53.31 \%$ of land use is in semi-arid class. In the semi-arid class, the largest land use class (1,24 million ha) is the cropland class. $35.98 \%$ of the total cropland areas within the Konya basin are irrigated cropland areas. $9.40 \%$ of the Konya Basin is covered by tree. As Land use change/conversion (2000-2018), the largest area (20521 ha) increase occurred in the agricultural class. In general, conversion is from other land classes to cropland class. The study will provide up to date data with both the thematic map and the numerical data for Konya basin planning in future.
\end{abstract}

Keywords: Konya Basin, Collect Earth, land use/cover class, monitoring.

\footnotetext{
*Sorumlu Yazar (Corresponding Author):

Ayhan ATEŞOĞLU (Dr.); Bartın Üniversitesi, Orman Fakültesi, Orman Mühendisliği

Bölümü, 74100, Bartın-Türkiye. Tel: +90 (378) 223 5166, Fax: +90 (378) 223 5062, E-

Geliş (Received) : 18.03 .2019

mail: aatesoglu@bartin.edu.tr ORCID: 0000-0002-4030-7782 


\section{Giriş}

Su ve toprak gibi doğal kaynakların kullanılması günümüzde sürdürülebilirlik ilkesi ve çevreyle uyumlu şekilde ele alınmaktadır. Havza yönetimi kavramı 1992' de uluslararası Rio Birleşmiş Milletler Çevre ve Kalkınma Konferansı'nda ilke kez önem kazanmıştır. Kalkınma ölçütlerinden birisi olarak kabul edilen havza yönetimi, havza içerisindeki doğal kaynakların sürdürülebilirlik çerçevesi içerisinde yerel halkın kullanımına sunulması manası taşımaktadır. Bu bağlamda bütünleşik bir kavram niteliğindedir. Havza esasen sürdürülebilir ekolojik bir sürecin işlediği bir birimdir. Havza içerisindeki tüm kaynakların kullanımı tüm ekolojik koşulları tetikleyebilmektedir. Bu nedenle, havzadaki planlama ve geliştirme çalışmaları tek taraflı bir amaç için gerçekleştirilemez. Toplumsal kalkınma hedefleri doğrultusunda sürdürülebilirlik ilkesi çerçevesinde havzadaki doğal kaynakların kullanımı salt olarak ele alınmalıdır (Heathcote, 1998; Reimold, 1998, Förch and Schütt, 2004)

Havza içerindeki bütünleşik anlayıș içerisinde en önemli faktör insandır. İnsan kaynaklı arazi kullanımı ve havzanın arazi örtüsü zamanla insan yararına değişmektedir. Bu sürecin takibi ve dengesi oldukça hassas bir konudur. Arazi kullanımı insan eliyle gerçekleştirilen ve halkın amacına yönelik kullanımlardır. Arazi örtüsü ise fiziksel bir anlam içermekle birlikte, ortamın toprak iklim vd. faktörlere göre oluşan peyzajıdır. Arazi örtüsü mevcut nüfus yapısına göre şekillenmektedir (Turnet et al. 1995). İnsan faaliyetleri doğrudan veya dolaylı olarak arazi örtüsünü değiștirmektedir. Bu nedenle havza içerindeki insan faktörü mevcut peyzajı insan eliyle şekillendirmektir (Mustard et al. 2005). Küresel ölçekte öncelikli tahrip edilen alanlar orman ve mera alanlarıdır. $\mathrm{Bu}$ alanlar toplumun öncelikli talebi olan gıda arzı noktasında değişime tabi olmuşlardır (Agarwall et al. 2000). İnsan müdahalesinin başta tarım ve yerleşim amaçlı arazi örtüsüne olan bu denli müdahaleleri havza alanları içerisinde büyük değişimlere ve problemlere neden olmuştur (Solbrig, 1993; Grübler, 1994). Havza içerindeki arazi kullanım/örtü değişiminin geçmiş, şimdi ve gelecekteki durumunu anlamak, havza içerisindeki biyoçeşitlilik ve ekosistem işlevi için son derece önemlidir. Mevcut durumun tespiti, insan kaynaklı arazi kullanımı/örtüsü ve mevcut iklim koşulları içerisindeki varlıkların net olarak ortaya konması gelecek senaryolar için önemli veriler sağlamaktadır (Gete, 2000). İklim değişikliği nedeniyle sürekli değişen çevresel etmenler mevcut durumun ortaya konması, bilhassa doğal ortam sayılan orman ve mera alanların tespiti, gida arzı noktasında tarım alanlarının kurak alanlar ile olan alansal ilişkilerinin belirlenmesi gelecek planlamalar için önem taşımaktadır (Belay 2002).

Havza içerisindeki arazi kullanımı mevcut durumun belirlenmesi ve değişimlerin takibi konularında Uzaktan Algılama (UA) ve Coğrafi Bilgi Sistemleri (CBS) önemli veri ve bilgi sağlayıcı konumundadırlar (Brown, 2003; Symeonekis and Koukoulas, 2009; Anil and Jaishankar, 2011; Kiran, 2013). Son y1llarda uzaktan algilama verileri yardımıyla artan coğrafi veri karşısında CBS'den oldukça sıklıkla yararlanılmaktadır. Uydu görüntü verilerinin mekânsal çözünürlükleri bölgesel ve lokal ölçeklerde daha doğru ve net sonuçlar üretirken, alanın büyümesi ile birlikte orta çözünürlüklü verilerin kullanımı oldukça yaygın durumdadır. Dolaysıyla makro havza ölçeğinde mekânsal çözünürlüğü yüksek uydu görüntü verilerinden daha çok orta çözünürlüklü görüntü verilerinin kullanımı yaygındır. Bu bağlamda alansal bazda daha büyük havzalar için orta çözünürlüklü veri kullanılırken, yüksek çözünürlüklü veriden elde edilecek salt objeye yönelik daha doğru ve hassas veri/bilgi üretimi kısıtlanmaktadır. Bu amaçla arazi izleme ve değerlendirme çalışmalarında maliyet, işgücü ve zaman faktörlerine uygun orta ve yüksek mekânsal çözünürlüğe sahip uydu görüntü verilerin CBS ile entegrasyonunu ortaya koyan izleme ve değerlendirme çalışmaları öne çıkmaktadır. Bu şekliyle daha geniş alanlar için daha doğru ve hassas veri üretimi sağlanabilmektedir (Atesoglu et al. 2017; Atesoglu et al. 2018).

Bu çalışmada, uzaktan algılama verileri ve coğrafi bilgi sistemleri entegre yaklaşımı çerçevesindeki Collect Earth yöntemi kullanılarak orman, mera ve tarım alanlarına ilişkin değerlendirmeler yapılmıştır. Her bir arazi kullanım/örtü sınıfa ilişkin kuraklık sınıflarına göre alansal dağılımlar belirlenmiştir. Ağaçla kaplı alan yüzdeleri, ağaç ve çalı yoğunlukları hesaplanarak odunsu vejetasyon miktarları hesaplanmıştır. Her bir arazi kullanım/örtü sınıfına ilişkin 2000-2018 yılları arasındaki arazi kullanım değişim ve yönleri alansal olarak hesaplanmıştır.

\section{Materyal ve Metot}

Çalışma alanı olarak KKH seçilmiştir. Türkiye'nin İç Anadolu Bölgesi'nde yer KKH Türkiye'nin toplam alanının \%7'sine denk gelen 4980534 ha alana sahiptir (Şekil 1). 3 milyon kiși yaşayan KKH'da nüfusun \%45'i kırsal alanlarda, \%55'i kentsel alanlarda yaşamaktadır. Havza genelinde, kırsal alanlardaki nüfus azalmakta, kentsel nüfus artmaktadır. Yapılan çalışmada kullanılan Hükümetler Arası İklim Paneli (IPCC) arazi kullanım sınıfları global anlamda birçok ülkenin sınıflarını kapsayacak şekilde altı ana sınıfa ayrılmıştır. Uluslararası bu sınıflandırmanın amacı tüm ülkeler için belirli bir standart üzere veri üretilmesini öngörmektedir. Arazi kullanım sınıflarına yönelik hesaplanabilecek diğer verilere yönelik (karbon stoğu değişimleri, sera gazı emisyon 
tahminleri, toprak organik karbon vb.) temel altlık olarak kullanılması amaçlanmıştır. Belirlenen altı sınıf için evrensel manada tüm ülkeler için sınıflandırılabilir temel sınıf olmaları, karbon tahmini için uygun sınıflar olması, uzaktan algılama veri/yöntemleri ile haritalanabilir ve tüm arazilere uygun olması bakımından uygun görülmüştür. IPCC arazi kullanım sınıfları orman, tarım, mera, yerleşim, sulak ve diğer alanlar olmak üzere altı ana sınıfta toplanmıştır. URL1, 2017; URL, 2018; URL3,2018).

Çalışmada ek altlık olarak Türkiye kurak alanlar arazi sınıfları haritası kullanılmıştır (Türkeş, 1999). Türkiye'deki kurak ve nemli arazilerin sınıflandırılmasına göre KKH'da çok kurak ve Kurak sınıflar yer almamaktadır. En büyük alan $26550.41 \mathrm{~km}^{2}$ alana sahip yarı kurak alan sınıfıdır. Bu sınıfı sırası ile $13362.26 \mathrm{~km}^{2}$ ile kuru yarı nemli, $7940.25 \mathrm{~km}^{2}$ ile yarı nemli, $1952.42 \mathrm{~km}^{2}$ ile nemli sınıflar takip etmektedir (Şekil 2).

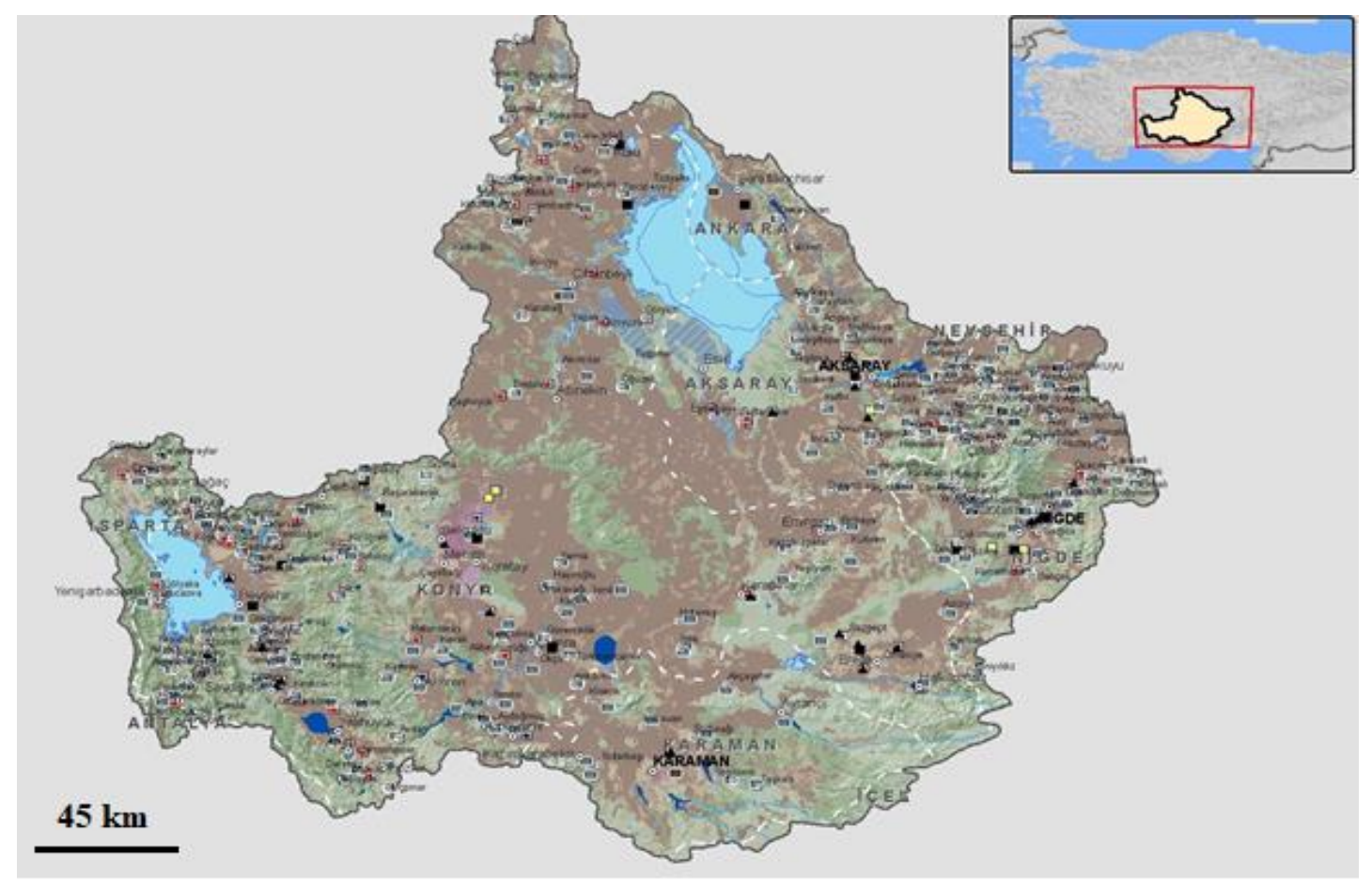

Şekil 1. Konya Kapalı Havzası (TUBİTAK-MAM, 2010).

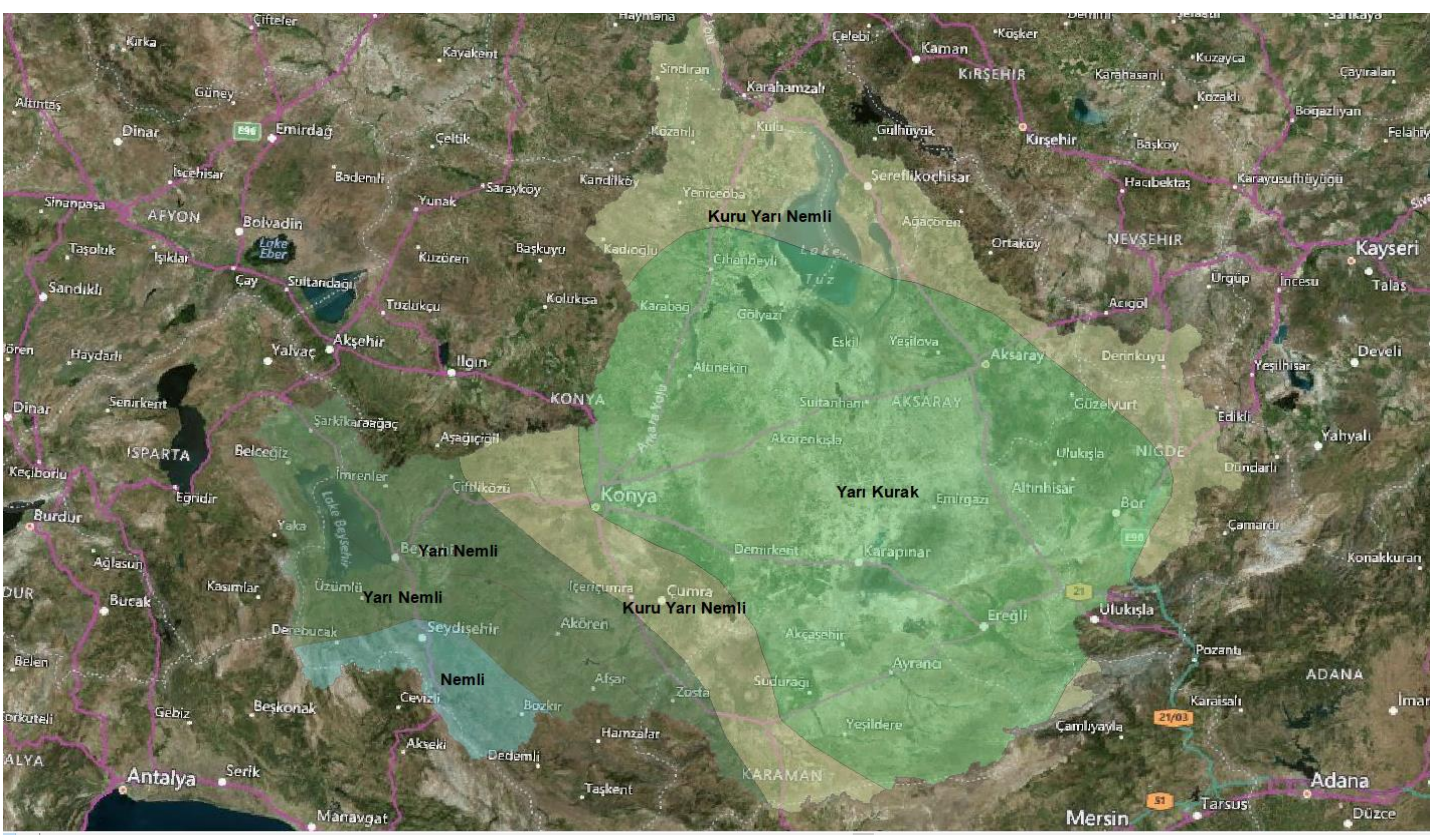

Şekil 2. Konya Kapalı Havzası kurak alan sınıfları. 
Proje alanı olarak seçilen KKH için kullanılacak olan yöntem, uzaktan algılama yöntemlerinden biri olan Open Foris/Collect Earth yöntemidir. Collect Earth yöntemi Java teknolojisi üzerine kurulu, uzaktan algılama ve CBS yazılımlarının entegresi olan çok amaçlı arazi izleme ve değerlendirme yazılımıdır. Kullanım alanları, ulusal ormancılık envanterini desteklemek, arazi örtü/kullanım sinıfları (Land Use, Land Use Change and Forestry; LULUCF) değerlendirmeleri, tarımsal ve kentsel alanların izlenmesi ve değerlendirilmesi, sosyo-ekonomik verilerin toplanması, arazi bozulumu ve iyileştirme alanlarının tespitine yöneliktir. Open Foris/Collect Earth kullanılarak genel arazi kullanımın ortaya koyarken objelere ait sayısal bilgi ve \% cinsinden yoğunluk miktarları hesaplanabilmektedir. Birleşmiş Milletler Gıda ve Tarım Örgütü' nün (FAO) bir aracı olan Collect Earth, küresel ormancılık envanteri ve kurak alanların değerlendirilmesi projesi kapsamında, FAO tarafından geliştirilmiştir. Collect Earth esnek ve etkin veri toplama, analiz ve raporlamayı kolaylaştıran bir yapıdadır. Collect Earth aslında bir bütünün parçalarından oluşmuş bir yapıda olup Google teknolojisini kullanan açık kaynak kodlu bir yazılımdır (Open Foris, 2016). Yöntem genel alana istatistiki olarak yeter düzeyde belirli büyüklükteki plotların değerlendirilmesi ve çıkan sonuçların tüm alana enterpole edilmesi prensibine göre çalışmaktadır (Şekil 3).

Yöntem dört ana kısımdan oluşur (Open Foris, 2016, Bastin vd. 2017):

- CBS; Değerlendirilmesi yapılacak plot alanların oluşturulduğu, konum, eğim ve bakı, yükseklik gibi topografik veri analizlerinin yapılarak veri tabanında kullanılacak öznitelik tablolarının oluşturulması için genel olarak açık kodlu QGIS programı kullanıldığı kısımdır.

- Collect; Veri tabanı oluşturma ve veri toplama penceresi oluşturma için kullanılan web tabanlı bir yazılımdır. Plot alanlarının boyutu, şekli, veri girişi pencerelerinin düzeni ve diğer tüm veri girişlerinin düzenlenebildiği kısımdır. Amaca yönelik objeye ait ulaşılabilir bilgilerin tümünün veri girişi olarak hazırlandığı veri tabanı kısmıdır.

- Collect Earth; Yöntemin temel kısmı veri girişinin olduğu yerdir. Google Earth, BingMaps ve Google Earth Engine ile birlikte kullanıcı amaçları dâhilinde geniş bir yelpazede yüksek çözünürlüklü uydu görüntülerinin kullanılmasına olanak sağlar. Ayrıca sunucu üzerinde oluşturulan veritabanı ile temsil noktalarının veri tablosu arasında bağlantı kuran kısımdır.

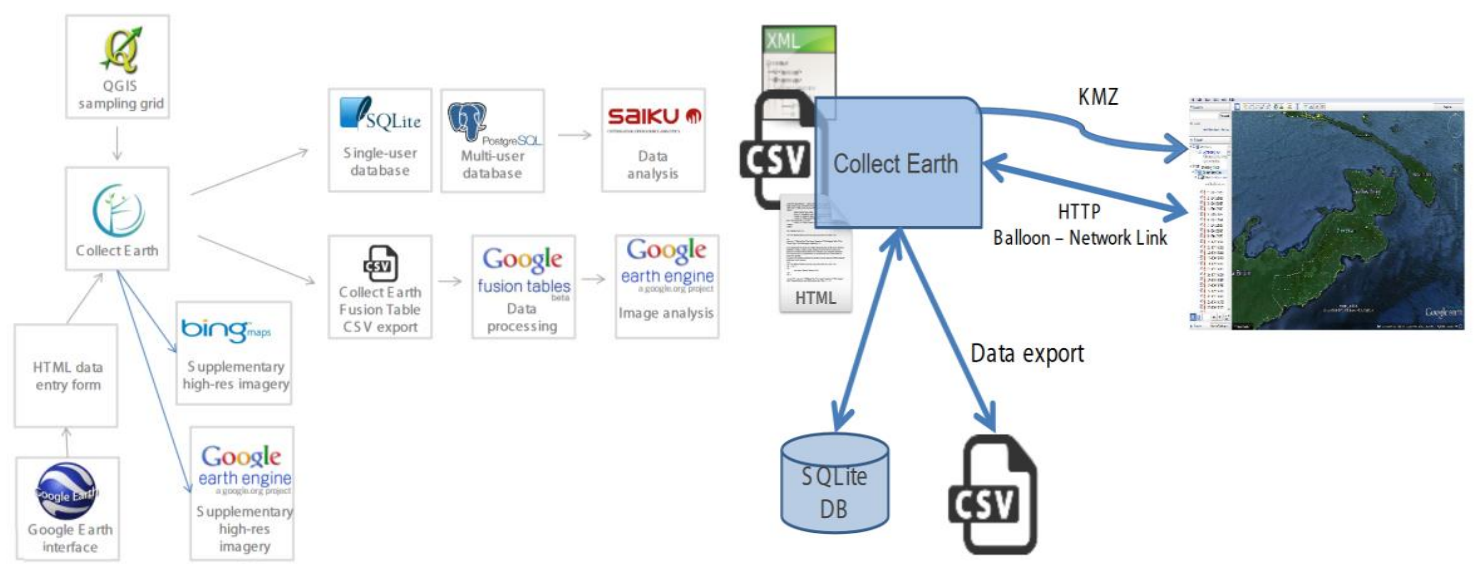

Şekil 3. Open Foris Collect Earth.

- SAIKU Analyst; SAIKU web tabanlı, veri görselleştirme ve veri sorgulamayı kolaylaştıran açık kaynak kodlu bir yazılımdır (URL4, 2017). Collect Earth üzerinden SAIKU web sitesinde ücretsiz kullanılabilmektedir. SAIKU Collect Earth programına dâhil olarak gelmektedir. SAIKU satır sütun mantığına göre veri kümelerinizin arasındaki rakamsal ilişkileri belirlemenizi, farklı sorgulamaları yapmanıza olanak sağlar. Collect Earth yöntemi Bey ve ark., 2016 yayınında ayrıntılı olarak irdelenmektedir.

Toplam 49805,34 $\mathrm{km}^{2}$ alanda, Collect Earth yöntemi kullanılarak KKH alanına toplam 8010 plot $(0,5$ ha büyüklüğünde) atılmıştır (Şekil 4). Her bir plot aralığı Doğu-Batı yönünde aralıkları yaklaşık $3 \mathrm{~km}$, KuzeyGüney yönünde aralıkları yaklaşı 3,8 km'dir. Tüm plotlar Collect Earth yöntem kapsamında Google Earth görüntüleri üzerinden ve Google Earth Engine ara yüzü ile Landsat, Modis, Sentinel vb. diğer uyduların hem görüntü hem de bu görüntülerden elde edilen NDVI (Normalleştirilmiş Fark Bitki Örtüsü İndeksi) ve NDWI 
(Normalleştirilmiş Fark Su İndeksi) grafik veriler üzerinden değerlendirmeye tabi tutulmuş ve çalışma alanının tümüne enterpole edilmiştir. Tüm rakamsal sonuçlar 2018 yılı itibari ile hesaplanırken arazi kullanım değişim ve yönü 2000-2018 yılları arasındaki 18 yıllık değişimi ve yönü yansıtmaktadır.
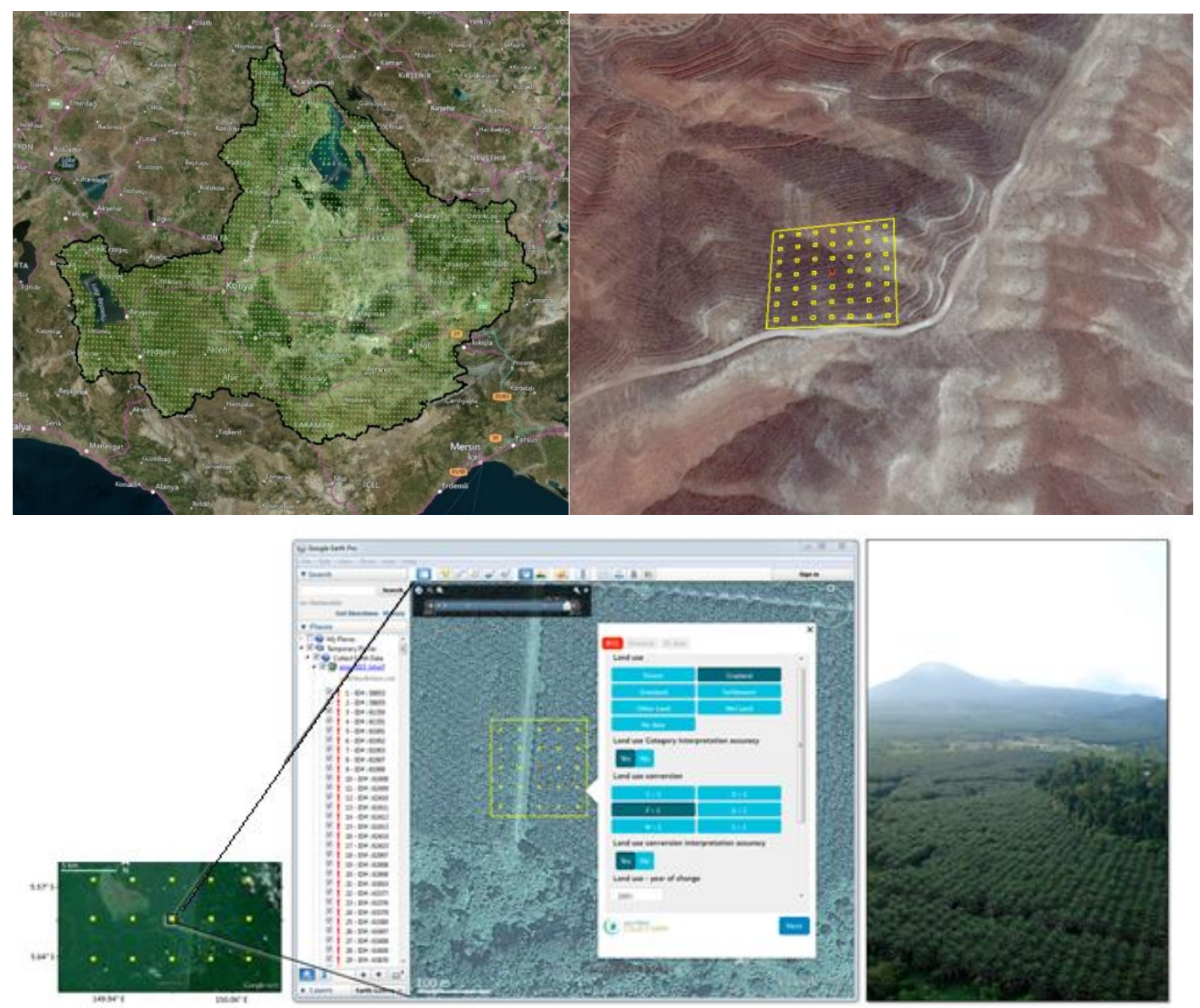

Şekil 4. Proje alanı ve Collect Earth yöntemine uygun plot alanlar.

\section{Bulgular}

Tüm pilot alanlara ilişkin sonuçlar arazi kullanım sınıfları, orman, tarım ve mera alanları ve arazi kullanım değişimleri ve yönü başlıkları kapsamında ayrı ayrı ele alınmıştır.

\subsection{Arazi Kullanım Sınıfları}

KKH'nın IPCC'ye göre arazi kullanım sınıfları dağılımları incelendiğinde, en büyük arazi sınıfını 2.27 milyon ha $(\% 45,7)$ ile tarım sınıfı oluşturmaktadır. Tarım sınıfını \%21,6 (1.08milyon ha) ile diğer arazi, \%20,8 (1.03 milyon ha) ile mera sınıfı takip etmektedir (Tablo 1). Arazi kullanım sınıflarının kuraklık sınıflarına göre dağılımları incelendiğinde, yarı kurak kuraklık sınıfında tarım alanları 1.24 milyon ha (\%25.06) olarak en büyük alansal sınıfı oluşturmaktadır. Yarı kurak alanlarda orman sınıfi 23.6 bin ha (\%0.47), mera sınıfi463,9 bin ha (\%9.29) alan kaplamaktadır. Mera sınıfı yine en fazla kapladığı alan yarı kurak alanlardadır (Tablo 2). Kuru yarı nemli alanlarda en fazla arazi kullanım sinıfi 732,46 bin ha ile tarım sınıfı, yarı nemli alanlarda 254,93 bin ha ile yine tarım sınıfı, nemli alanlarda 56,58 bin ha ile orman sınıfı oluşturmaktadır (Şekil 5).

\subsection{Orman, Mera, Ağaç ve Çalı}

Orman Alanları: IPCC tanımlamasına göre KHK'da toplam 258,04 bin ha orman alanı mevcuttur. Kuraklık sınıflarına göre dağılımı incelendiğinde en çok orman varlığı 152,33 bin ha $(\% 59,03)$ alan ile yarı nemli alanlarda bulunmaktadır. Bunu sırasıyla nemli $(\% 21,72)$ ve kuru_yarı nemli $(\% 9,7)$ alanlardaki orman varlıkları takip etmektedir. (Tablo 3). 
Tablo 1. Arazi kullanım sınıfları dağılımları.

\begin{tabular}{llllllll}
\hline IPCC Kullanım Sınıfı & Orman & Tarım & Diğer & Mera & Sulak & Yerleşim & Toplam (ha) \\
\hline Alan (ha) & 258043 & 2279480 & 1080668 & 1039010 & 200838 & 122493 & $\mathbf{4 9 8 0 5 3 2 . 0 0}$ \\
\hline
\end{tabular}

Tablo 2. Kuraklık sınıflarına göre arazi kullanım alansal dağılımları.

\begin{tabular}{lccccccc}
\hline \multirow{2}{*}{ Kuraklık Sınıfları } & \multicolumn{7}{c}{ Alan (ha) } \\
\cline { 2 - 7 } & Orman & Tarım & Diğer & Mera & Sulak & Yerleşim & Toplam (ha) \\
\hline Kuru yarı nemli & 25493 & 732468 & 182806 & 277940 & 81454 & 36064 & 1336225 \\
Nemli & 56583 & 43525 & 37307 & 48500 & 4353 & 4974 & 195242 \\
Yarı kurak & 23628 & 1248553 & 744282 & 463855 & 103839 & 70884 & 2655041 \\
Yarı nemli & 152338 & 254934 & 116275 & 248715 & 11192 & 10570 & 794025 \\
Toplam (ha) & 258042 & 2279480 & 1080670 & 1039011 & 200838 & 122492 & $\mathbf{4 9 8 0 5 3 2 . 0 0}$ \\
\hline
\end{tabular}

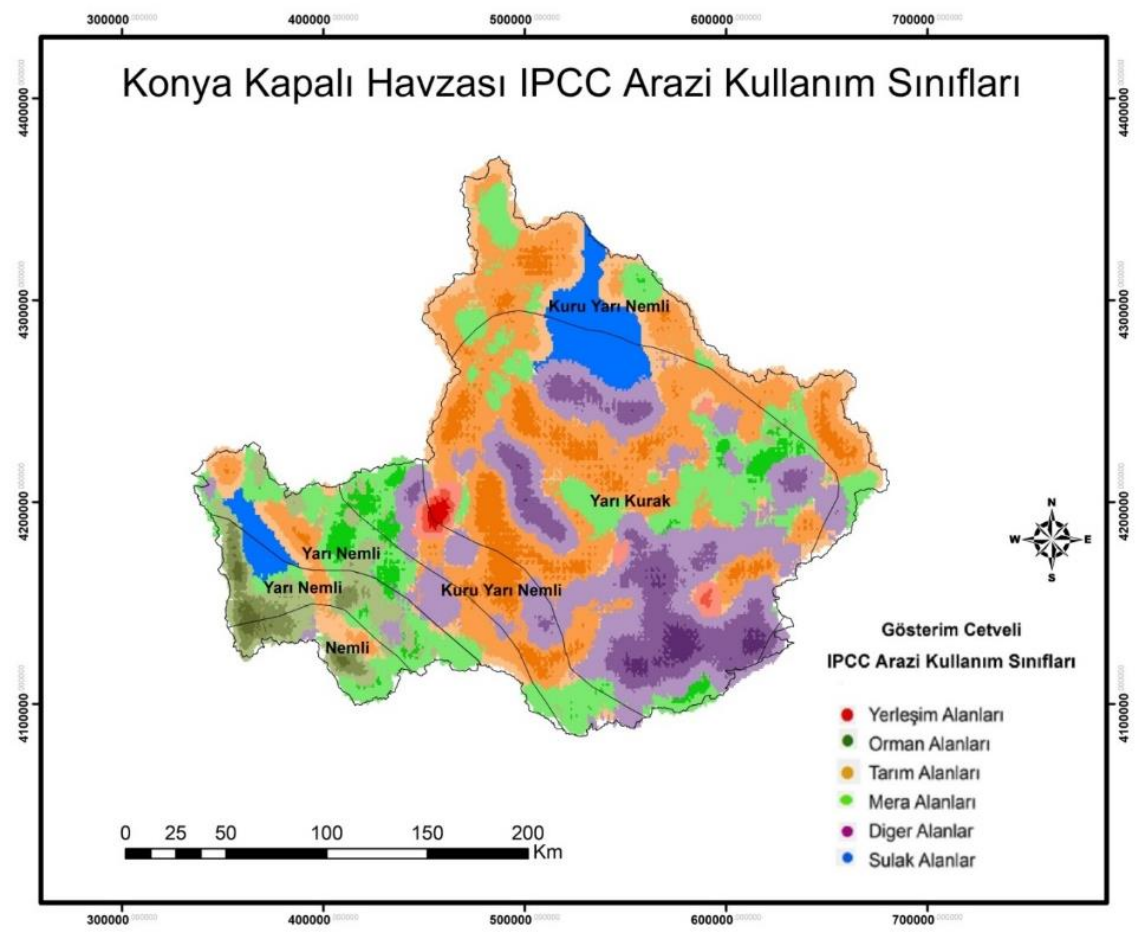

Şekil 5. IPCC arazi kullanım sınıfları.

Tablo 3. Kuraklık sınıflarına göre IPCC orman alanları.

\begin{tabular}{ll}
\hline Kuraklık Sınıfları & Orman Alanı (ha) \\
\hline Kuru yarı nemli & 25493 \\
Nemli & 56583 \\
Yarı kurak & 23628 \\
Yarı nemli & 152338 \\
Toplam & $\mathbf{2 5 8 0 4 3}$ \\
\hline
\end{tabular}

Orman alanı ağaçla kaplama yüzdelerine göre alansal dağılımları incelendiğinde; \%20-29 ağaç ile kaplı alanların miktarı 51,60 bin ha (\%19,78) ilk sırada yer almaktadır. Bu oranı sırası ile 42,28 bin ha ile \%60-69 ağaç ile kaplı alanlar, 36,68 bin ha ile \%70-79 ağaç ile kaplı alanlar, 29,22 bin ha ile \%90-100 ağaç ile kaplı alanlar izlemektedir. (Tablo 4). 
Tablo 4. Orman arazisi ağaç kaplama yüzdesi ve alanları.

\begin{tabular}{lcccccccccccc}
\hline $\begin{array}{l}\text { Ağaçla } \\
\text { kaplama } \\
\text { yüzdesi }\end{array}$ & $\mathbf{0 \%}$ & $\mathbf{6 \%}$ & $\mathbf{1 0 - 1 9 \%}$ & $\mathbf{2 0 - 2 9 \%}$ & $\mathbf{3 0 - 3 9 \%}$ & $\mathbf{4 0 - 4 9 \%}$ & $\mathbf{5 0 - 5 9 \%}$ & $\mathbf{6 0 - 6 9 \%}$ & $\mathbf{7 0 - 7 9 \%}$ & $\mathbf{8 0 - 8 9 \%}$ & $\mathbf{9 0 - 1 0 0 \%}$ & Toplam \\
\hline $\begin{array}{l}\text { Alan } \\
\text { (ha) }\end{array}$ & 12436 & 622 & 1244 & 51609 & 27981 & 19273 & 15545 & 42282 & 36686 & 21141 & 29224 & $\mathbf{2 5 8 0 4 3}$ \\
\hline
\end{tabular}

Kuraklık sınıfları bazında, ağaç kaplama yüzdelerine göre incelendiğinde en çok orman varlı̆̆ bulunan yarı nemli alanlarda ağaç kaplama yüzdelerine göre normal bir dağılım söz konusudur. Yarı nemli alanlarda ağaç kaplama oranı \%20-29 olan yerlerde 35,44 bin ha orman varlığı tespit edilmiştir (Tablo 5).

Tablo 5. Kuraklık sınıflarına göre ağaç kaplama yüzdeleri ve alanları.

\begin{tabular}{|c|c|c|c|c|c|c|c|c|c|c|c|c|}
\hline \multirow[b]{2}{*}{$\begin{array}{l}\text { Kuraklık } \\
\text { Sınıfları }\end{array}$} & \multicolumn{11}{|c|}{ Orman Alanı (ha) } & \multirow[b]{2}{*}{$\begin{array}{c}\text { Toplam } \\
\text { (ha) }\end{array}$} \\
\hline & 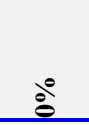 & 8̊ & $\frac{\stackrel{\circ}{\sigma}}{\stackrel{1}{6}}$ & 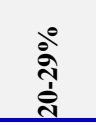 & $\begin{array}{l}\stackrel{\circ}{0} \\
\text { हे }\end{array}$ & $\begin{array}{l}\stackrel{0}{0} \\
\stackrel{f}{f} \\
o\end{array}$ & 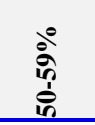 & 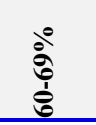 & $\begin{array}{l}\stackrel{\circ}{\circ} \\
\stackrel{1}{8}\end{array}$ & $\begin{array}{l}\stackrel{0}{\circ} \\
\text { के } \\
\text { के }\end{array}$ & 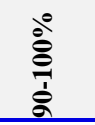 & \\
\hline $\begin{array}{l}\text { Kuru yarı } \\
\text { nemli }\end{array}$ & 4353 & & 622 & 4353 & 1865 & 4353 & 1865 & 3109 & 3109 & & 1865 & 25493 \\
\hline Nemli & 1244 & & & 6218 & 7461 & 4353 & 3109 & 9327 & 9949 & 8083 & 6840 & 56583 \\
\hline Yarı kurak & 2487 & 622 & & 5596 & 1244 & 1244 & 1244 & 3109 & 2487 & 1244 & 4353 & 23628 \\
\hline Yarı nemli & 4353 & & 622 & 35442 & 17410 & 9327 & 9327 & 26737 & 21141 & 11814 & 16167 & 152338 \\
\hline Toplam & 12436 & 622 & 1244 & 51609 & 27981 & 19275 & 15545 & 42282 & 36686 & 21141 & 29224 & 258043 \\
\hline
\end{tabular}

Mera Alanları; KHK'da toplam mera alanı 1.03 milyon ha olarak hesaplanmıştır (Şekil 6). Mera alanları içerisinde ağaç ve çalı varlıklarına göre de sınıflandırma yapılarak toplam mera sınıfı oluşturulmuştur. Ağaçlı mera varlığ 54096 ha, çalılı mera varlığ 125601 ha, hem ağaçlı hem de çalılı mera varlığı 13679 ha, taşlı mera varlığı 39173 ha'dır. Geri kalan mera alanları odunsu vejetasyon içermemektedir.

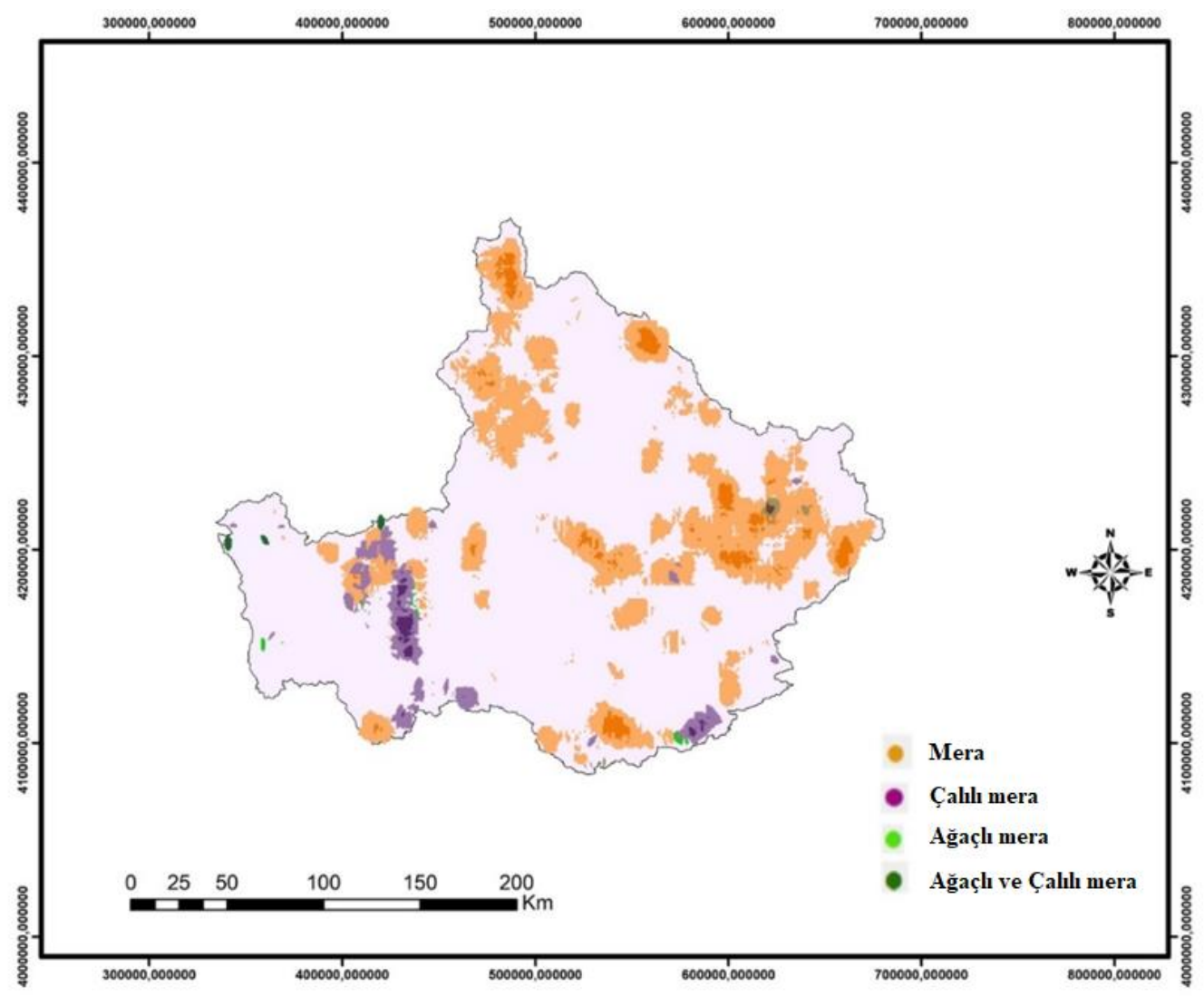

Şekil 6. Mera alanları. 
Ağaçla kaplı alanlar; Yapılan analizler neticesinde KKH’nın ağaçla kaplı toplam alanı 468,20 bin ha olarak hesaplanmıştır. Bu oranın KKH yüzölçümüne oranı \%9,40 olarak hesaplanmıştır.

Kuraklık sınıflarına göre, yarı kurak alanlarda 2,56 milyon ha $(\% 51,46)$ alan ağaç varlığı bulundurmamaktadır. Tamamen ağaçla kaplı (\%90-100) alan ise 4,35 bin ha' dır. Kuru yarı nemli alanlarda ise ağaçla kaplı olmayan arazi varlığı 1,25 milyon ha $(\% 25,28)$ 'dir. Fakat en fazla ağaçla kaplı alansal varlıklar bu kuraklık sınıfinda yer almaktadır. (Tablo 6). KKH'nda hektarda ortalama 3,51 adet ağaç bulunmaktadır. Arazi kullanım sınıflarına göre ağaç yoğunluğu en çok orman sınıfında hektar başına 50-51 adet olarak gerçekleşmiştir. Bu rakamı hektar başına 4-5 ağaçla yerleşim sınıfı, 1-2 ağaçla mera sınıfı takip etmektedir (Tablo 7). Ayrıca havza sınırları içerisinde hektarda ortalama 2,67 adet çalı bulunmaktadır:

Tablo 6. Kuraklık sınıflarına göre ağaçla kaplı alanlar.

\begin{tabular}{|c|c|c|c|c|c|c|c|c|c|c|c|c|c|c|c|}
\hline \multirow[b]{2}{*}{$\begin{array}{l}\text { Kuraklık } \\
\text { Sınıfları }\end{array}$} & \multicolumn{14}{|c|}{ Ağaçla kaplı alan (ha) } & \multirow[b]{2}{*}{$\begin{array}{c}\text { Toplam } \\
\text { (ha) }\end{array}$} \\
\hline & $\stackrel{\circ}{0}$ & $\therefore$ & $\frac{8}{8}$ & $\frac{8}{6}$ & $\stackrel{0}{\infty}$ & $\frac{\circ}{6}$ & $\begin{array}{l}\text { ลे } \\
\text { ते }\end{array}$ & ڤ̊ & 守 & ڤั & 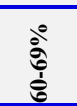 & 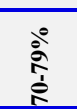 & $\begin{array}{l}\stackrel{0}{0} \\
\text { के } \\
0\end{array}$ & 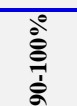 & \\
\hline $\begin{array}{l}\text { Kuru Yarı } \\
\text { nemli }\end{array}$ & 1259746 & 1865 & 3731 & 6840 & 9327 & 22384 & 11192 & 2487 & 6218 & 2487 & 3109 & 4353 & 622 & 1865 & 1336226 \\
\hline Nemli & 123736 & & 1865 & 1865 & 2487 & 8705 & 6218 & 7461 & 4974 & 3731 & 9327 & 9949 & 8083 & 6840 & 195241 \\
\hline Yarı kurak & 2563016 & 3731 & 6218 & 7461 & 9327 & 35442 & 8705 & 5596 & 1865 & 1865 & 3109 & 3109 & 1244 & 4353 & 2655041 \\
\hline Yarı nemli & 565207 & 4974 & 11192 & 7461 & 11192 & 39173 & 38551 & 19897 & 9949 & 9327 & 27359 & 21763 & 11814 & 16167 & 794026 \\
\hline $\begin{array}{l}\text { Toplam } \\
\text { (ha) }\end{array}$ & 4511705 & 10570 & 23006 & 23627 & 32333 & 105704 & 64666 & 35441 & 23006 & 17410 & 42904 & 39174 & 21763 & 29225 & 4980534 \\
\hline
\end{tabular}

Tablo 7. Arazi kullanım sınıflarına göre hektar başına düşen ağaç sayısı.

\begin{tabular}{lc}
\hline \multicolumn{1}{c}{ Arazi Kullanımı } & $\begin{array}{c}\text { Hektar Başına } \\
\text { (ad/ha) }\end{array}$ \\
\hline Orman & 50,29 \\
Tarım Arazisi & 0,97 \\
Diğer Arazi & 0,41 \\
Mera Arazisi & 1,19 \\
Sulak Arazi & 0,04 \\
Yerleşim Arazisi & 4,98 \\
\hline
\end{tabular}

\subsection{Tarım Alanları}

Alt arazi kullanım türlerine göre toplam tarım alanlarının \%62,96’ s1 (1,43 milyon ha) sulanmayan tarım alanları içerisinde yer almaktadır. Bu alt arazi kullanım sınıfını \%35,92 (818,89 bin ha) sulanan tarım, \%1,03 oranla meyve bahçesi takip etmektedir (Tablo 8). Kuraklık sınıflarına göre tarım alanları incelendiğinde (\%0 olan alanlar tarım sınıfı içinde yer almamaktadır.), tarım arazisi olarak \%90-100 oranında kaplı alanlar en çok 1,15 milyon ha ile yarı kurak alanlardadır. Kuru yarı nemli alanlarda ise \%90-100 oranında kaplı alanlar 669,04 bin ha'dır. Nemli ve yarı nemli alanlarda ise tarım arazisi varlığı oldukça düşük seviyelerde gerçekleşmiştir (Tablo 9).

\subsection{Arazi Kullanım Değişimleri ve Yönü}

Önceki arazi kullanımları ve güncel arazi kullanım sınıfları değişimleri 2000 yılından 2018 yılına kadar olan 18 y1llık süreci göstermektedir.

Tablo 8. Alt arazi kullanım türlerine göre tarım alanları.

\begin{tabular}{lll}
\hline \multicolumn{3}{c}{ Tarım Alanları } \\
\hline Alt Arazi Kullanımı Türü & Alan (ha) & \% \\
\hline Sulanan Tarım & 82.0141 & 35,98 \\
Sulanmayan Tarım & 1.435 .090 & 62,96 \\
Meyve Bahçesi & 23.628 & 1,03 \\
Sera & 622 & 0,03 \\
TOPLAM & 2.279 .480 & 100 \\
\hline
\end{tabular}


Sonuçlar incelendiğinde tarım alanının geçmişe göre 20521 ha arttığı görülmüştür. Arazi kullanımının değişim yönü en çok diğer arazi sınıfından tarım arazi sınıfına doğru gerçekleşmiştir. Yerleşim arazi sınıfına da orman, mera ve tarım arazi sınıflarından geçişler gözlenmiştir (Tablo 10).

Tablo 9. Kuraklık sınıflarına göre tarım arazi sınıfı ile kaplı alanlar.

\begin{tabular}{|c|c|c|c|c|c|c|c|c|c|c|c|c|c|c|c|}
\hline \multirow[b]{2}{*}{$\begin{array}{l}\text { Kuraklık } \\
\text { Sinıfları }\end{array}$} & \multicolumn{14}{|c|}{ Tarım arazisi ile kaplı alan (ha) } & \multirow[b]{2}{*}{$\begin{array}{c}\text { Toplam } \\
\text { (ha) }\end{array}$} \\
\hline & $\begin{array}{l}* \\
* \\
0\end{array}$ & $\stackrel{4}{\circ}$ & $\stackrel{a}{\circ}$ & bे & $\stackrel{\infty}{\infty}$ & $\frac{\circ}{\circ}$ & 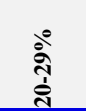 & ڤ̊ & 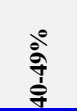 & 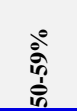 & $\begin{array}{l}\stackrel{0}{0} \\
\hat{b} \\
\text { ठิ }\end{array}$ & $\begin{array}{l}\stackrel{\circ}{\circ} \\
\stackrel{1}{R}\end{array}$ & $\begin{array}{l}\stackrel{\circ}{\infty} \\
\text { ळे } \\
\grave{\infty}\end{array}$ & 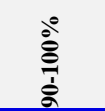 & \\
\hline $\begin{array}{l}\text { Kuru yarı } \\
\text { nemli }\end{array}$ & 583239 & 622 & 1244 & 622 & & 8083 & 9949 & 9949 & 6218 & 6840 & 9327 & 8705 & 22384 & 669045 & 1336227 \\
\hline Nemli & 148608 & & & 622 & & 622 & 622 & 1244 & 1865 & & 622 & 1244 & 5596 & 34198 & 195243 \\
\hline $\begin{array}{l}\text { Yarı } \\
\text { kurak }\end{array}$ & 1374777 & & 1865 & 2487 & 622 & 14301 & 18032 & 14923 & 8705 & 7461 & 13679 & 15545 & 31711 & 1150928 & 2655040 \\
\hline $\begin{array}{l}\text { Yarı } \\
\text { nemli }\end{array}$ & 529765 & 1244 & 622 & & 622 & 3109 & 5596 & 4353 & 4353 & 3731 & 5596 & 6840 & 16167 & 212030 & 794024 \\
\hline Toplam & 2636389 & 1866 & 3731 & 3731 & 1244 & 26115 & 34199 & 30469 & 21141 & 18032 & 29224 & 32334 & 75858 & 2066205 & 4980534 \\
\hline
\end{tabular}

Tablo10. Arazi kullanım değişimleri (ha) ve yönü (2000-2018).

\begin{tabular}{|c|c|c|c|c|c|c|c|}
\hline \multirow{2}{*}{$\begin{array}{l}\text { Önceki } \\
\text { Arazi } \\
\text { Kullanımı (ha) }\end{array}$} & \multicolumn{7}{|c|}{$\begin{array}{c}\text { Güncel } \\
\text { Arazi Kullanımı (ha) }\end{array}$} \\
\hline & Orman & $\begin{array}{c}\text { Mera } \\
\text { Arazisi }\end{array}$ & $\begin{array}{c}\text { Tarım } \\
\text { Arazisi }\end{array}$ & $\begin{array}{c}\text { Yerleşim } \\
\text { Arazisi }\end{array}$ & $\begin{array}{c}\text { Sulak } \\
\text { Arazi }\end{array}$ & Diğer Arazi & Toplam \\
\hline Orman & 258043 & 1244 & & 622 & & 622 & 260530 \\
\hline Mera Arazisi & & 1037145 & 6218 & 1244 & & & 1044606 \\
\hline Tarım Arazisi & & & 2256472 & 1244 & 1244 & & 2258959 \\
\hline $\begin{array}{l}\text { Yerleşim } \\
\text { Arazisi }\end{array}$ & & & & 119384 & & & 119384 \\
\hline Sulak Arazi & & 622 & & & 199594 & 622 & 200838 \\
\hline Diğer Arazi & & & 16788 & & & 1079427 & 1096215 \\
\hline Toplam & 258043 & 1039010 & 2279480 & 122493 & 200838 & 1080670 & 4980532 \\
\hline
\end{tabular}

\section{Tartışma ve Sonuç}

KKH için gerçekleştirilen çalışma sonucunda havzanın durum tespitine yönelik sonuçlar aşağıdaki gibi siralanmaktadır;

- 2018 yılı itibari ile arazi kullanım dağılımları; Tarım \%45,77, Orman \%5,18, Mera \%20,86, Diğer \%21,70, $\mathrm{Su} \%$ 4,03 ve Yerleşim \%2,46 olarak tespit edilmiştir. 2014 yılında "Konya'da suyun bugünü raporu” isimli çalışmada (WWF, 2014) Coordination of Information on the Environment (CORINE) 1. Düzeye göre yapılan sınıflandırmada özellikle tarım alanlarının havzanın \%56'sını kapladığı tespit edilmiştir. Benzer şekilde Türkiye Bilimsel ve Teknolojik Araştırma Kurumu (TUBITTAK) Marmara Araştırma Merkezi (MAM) tarafından gerçekleştirilen "Havza koruma eylem planlarının hazırlanması-Konya kapalı havza" projede de (URL6, 2018) Çevre ve Orman Bakanlığı verilerine dayandırarak verdiği tarım alanları varlığı \%55,54 olarak belirtilmiştir. Her iki çalışmada CORINE düzey_1 verilerine dayanmaktadır. Gerek Doğal Hayatı Koruma Vakfı (WWF) gerekse TUBITAK'ın gerçekleştirilen çalışmadaki diğer kullanım alanlarından orman ve yarı doğal alanlar, gerçekleştirilen çalışmada mera ve diğer alanlar gibi uyumsuz sınıflar noktasındaki tutarsızlıkların olması, Konya kapalı havzanın uluslararası geçerliliği olan bir sınıflamaya göre arazi kullanım sınıflandırmasının yapılmadığından kaynaklı bir durumun göstergesidir. Özellikle kuraklık noktasında KKH'nın izleme ve değerlendirmesi için geçmişten günümüze aynı sınıflar altındaki değişimlerin gözlenmesi gerekliliği esas olmalıdır. Bu yönü ile dünya ölçeğinde kabul edilen ve çalışmada kullanılan IPCC arazi kullanım sınıflandırması sonuçlarına göre Konya kapalı havza planlamalarında yer alması önemli olacaktır.

- Kuraklık sınıflarına göre arazi kullanım dağılımları incelendiğinde, arazi kullanımlarının \%53,31 "yarı kurak" sınıfta yer almaktadır. Yarı kurak sınıf içerisinde ise en büyük arazi kullanım sınıfı (1,24 milyon ha) Tarım sınıfıdır. Havzada yağış ve su azlığı olduğu düşünüldüğünde yarı kurak sınıfında yer alan tarım alanlarının planlanması daha da önem kazanmaktadır. 
- Tarım alanlarının alt kullanımlara göre sınıflandırılmasında Collect Earth Engine içerisinde yer alan su indeksi (NDWI) kullanılarak sulanan alan tespiti gerçekleştirilmiştir. Konya kapalı havza içerindeki toplam tarım alanlarının \%35,98'i sulanan tarım alanlarıdır. WWF ve TUBITAK'ın havzaya yönelik gerçekleştirdiği çalışmalarda CORINE bazlı tematik harita ile gösterilmiş bir alan belirtilmemiştir. Gerçekleştirilen çalışmada havzada 2018 yılı itibari ile 0,82 milyon ha alanın sulanmakta olduğu tespit edilmiştir.

- KKH'nda toplam 258,04 bin ha orman alanı mevcuttur. Bu alanın \% 59'u yarı nemli alanlarda yer almaktadır. Orman alanlarının arazi yüzeyini örtme derecesine göre ise, \% 50 ve üzerinde orman arazi örtüsü ile kaplı alanlar tüm orman varlığının \%56,14'dür.

- KKH'nın toplam mera alanının \%18,6'sı ağaç ve çalı gibi odunsu türlerle, \%3.8'i taşlık alanlarla kaplıdır.

- KKH'nın \%9,40'1 ağaç içeren ve ağaçla kaplı alanlar içerisinde yer almaktadır. Hektarda ortalama 3,51 adet ağaç bulunmaktadır. Bu oran yerleşim sınıfı için hektarda 4,98 ağaçtır. Ayrıca hektarda ortalama 2,67 adet çalı bulunmaktadır.

- Arazi kullanım değişimleri incelendiğinde, 2000-2018 yılları arasında en büyük artış 20521 ha ile tarım sınıfında yaşanmıştır. Yerleşim sınıfı içerisinde de 3109 ha bir alan artışı gözlenmiştir. Tarım arazilerindeki artışın büyük bir bölümü (16788 ha) diğer sınıflardan yaşanırken, 6218 ha mera alanı da tarım alanı dönüşmüştür. Buna karşın 1244 ha alan tarım alanı iken yerleşim alanına dönüşmüştür. Genel olarak değişim diğer alanlardan tarım alanına doğru yaşanmıştır. Yerleşim alanlarına olan değişim ise orman, tarım ve mera alanlarından gerçekleşmiştir. Bu yönü ile bölgenin gıda arzı noktasında tarım alanı artışı gözlenmektedir.

Konya kapalı Havza çalışmalarındaki en büyük risk, bütüncül havza yönetimi içerisindeki yer üstü ve yer altı su kaynaklarının durumudur. Tunçok ve Bozkurt, 2015'de yaptığı çalışmada havzanın tarıma olan katkısı belirtilmiş ve \% 57 oranında tarım varlığından bahsedilmiştir. Sulanan alanlara ilişkin olarak da \%54'nün su tüketimi fazla olan bitkilerin seçimi ve gelecekte su bütçesine olan olumsuz etkilerine değinilmiştir. Çalışmada sulanan alan olarak ve ne kadar alanın sulandığı belirtilmemiştir. Gerçekleştirilen çalışma ile 820141 ha alan sulanan olarak tespit edilmiştir. Bu verilerin yersel veri ile desteklenerek ne kadarlık bir alanda sulama yapıldığı, ekime tercih edilen ürün ve su miktarları ile hesaplanarak su bütçesi hesaplamaları yapılması daha doğru sonuçlar verecektir. Benzer olarak Üstün ve ark., 2007 ve Başçitçi ve ark., 2013’ de yaptığ çalışmalar ve CBS ortamında analiz edilerek özellikle tarım amaçlı su kullanımı kaynaklı olumsuzluklar belirtilmiştir. Kaçak su kuyularına değinilen çalışmada sulanan tarım alanlarına ilişkin verilerin tespiti ve gerek vahşi gerekse kaçak sulama altyapılarına yönelik tespit çalışmaları mümkündür. Sulanan alan miktarı ve arazide belirlenecek olan ürün cinsi kullanılarak kullanılan yaklaşık su miktarı yaklaşım hesapları ile mümkün olacaktır. 2014 yılında "Konya'da suyun bugünü raporu” isimli WWF-Türkiye çalışmasında ve Tubitak MAM tarafından gerçekleştirilen "Havza koruma eylem planlarının hazırlanması-Konya kapalı havza" projesinde Konya kapalı havza arazi kullanım sınıfları CORINE 1. Düzey sınıfları baz alınarak yapılmıştır. Minimum haritalama birimi 25 ha olan CORINE arazi sınıfları haritası arazi örtü/kullanımına yönelik planlamalarda yeterli olmamaktadır.

Gerçekleştirilen çalışmada tercih edilen yüksek ve orta çözünürlüklü veri entegrasyonuna ilişkin Collect Earth yöntemi raporlama çalışmaları daha doğru ve net sonuçlar üretmektedir. Üretilen rakamsal veriler, plot alanlara ilişkin yüksek çözünürlüklü ve orta çözünürlüklü uydu görüntülerinden üretilen grafik veriler yardımıyla genel alana enterpole edilmesiyle hesaplanmaktadır. Bu bağlamda, yapılan çalışmanın istatistiki olarak doğruluğunu alanı temsil eden nokta sayısı ile doğru orantılı olmaktadır. Bu çalışma için kullanılan 8010 yarım hektarlık plot alanlara ilişkin değerlendirmeler, oldukça keskin sonuçlar vermiştir. Daha hassas çalışma için plot sayısının arttırılması elzem olmakla birlikte, genel olarak değişkenliği az arazi örtü/kullanım alanlarının çok olduğu araziler için fazlaca plot sayısının artırılmasına gerek yoktur. Her bir plot için yüksek çözünürlüklü (yaklaşım $1 \mathrm{~m}$ Google Earth görüntü verisi) veri kullanıldığı için yapılan tüm değerlendirmeler yer gerçeği olarak kabul edilmekte ve ayrıca arazi çalışmasına gereksinim duyulmamaktadır. Collect Earth yöntemi kullanılarak rakamsal veri üretimine yönelik alansal bilgiler, birçok planlamada daha hassas ve doğru veri desteği sağlayacaktır. Ssonuçları itibariyle yıllar bazında izleme ve değerlendirme çalışması için en uygun yöntemlerden birisidir. Konya kapalı havza gibi alansal olarak büyük bir alan için yıllar bazında izleme ve değerlendirme çalışmalarını da mümkün ve etkin kılmaktadır.

Gerek tarım gerekse diğer kullanım alanlarına yönelik vejetasyon bazında yapılacak bir risk haritası kayıplar (arazi bozulumu/tahribatı), kazançlar (arazi iyileşmesi/vejetasyon artışı) noktasında gerçekleştirilmesi, KKH'nın genel durumunu daha net belirlenmesi için planlanması gereken öncül çalışmalar arasında yer almalıdır. Ayrıca 
uzaktan algılama verilerinden elde edilecek verilen arazi ölçümleri ve doğrulamaları ile de mutlak tespiti ve onayı gerekmektedir. Nihai havza koruma eylem planları bu çerçevede ele alınması ve yıllar bazında belirli aralıklarla yapılması zorunlu çalışmalar olmalıdır.

\section{Teşekkür}

Bartın Üniversitesi Bilimsel Araştırma Projeleri Komisyonu tarafından desteklenmiştir (Proje No: 2017-FEN-B002). Projeye olan katkılarından dolayı Orman ve Su İşleri Bakanlığı, Çölleşme ve Erozyonla Mücadele Genel Müdürlüğ̈̈'ne teşekkür ederiz.

\section{Kaynaklar}

1. Anil, N.C., Jaishankar, G. (2011). Studies on Land Use/Land Cover and change detection from parts of South West Godavari District, A.P - Using Remote Sensing and GIS Techniques, J. Ind. Geophys. Union, 15(4), 187-194.

2. Atesoglu, A., Arslan, M., Yılmaz, M., Arıkan, T. B., Yıldı, S. (2017). Collect Earth Programı kullanılarak Türkiye kurak alanlarının izleme ve değerlendirilmesi, Afyon Kocatepe Üniversitesi Fen ve Mühendislik Bilimleri Dergisi, 2149-3367, 17, 1, 252.

3. Atesoglu, A., Tunay, M., Arıkan, T. B., Yıldız, S. (2018). Ortadoğu toz kaynaklarının tespiti ve FiratDicle nehir havzası (suriye-irak) tarım alanları üzerindeki etkisinin değerlendirilmesi, Doğal Afetler ve Çevre Dergisi, 2528-9640, 4, 1, 2528.

4. Bastin, J. F., Berrahmouni, N., Grainger, A. (2017). The extent of forest in dryland biomes. Science, 356, 635-638.

5. Başçiftçi, F., Durduran, S. S., İnal, C. (2013). Konya kapalı havzasında yeraltı su seviyelerinin coğrafi bilgi sistemi (CBS) ile haritalanmas1 electronic. Journal of Map Technologies, 5(2), 1-15.

6. Başçiftçi, F., Durduran, S. S., İnal, C. (2013). Konya kapalı havzasında yeraltı su seviyelerinin coğrafi bilgi sistemi (CBS) ile haritalanmas1. Harita Teknolojileri Elektronik Dergisi, 5(2), 1-15.

7. Bey, A., Sánchez-Paus Díaz, A., Maniatis, D., Marchi, G., Mollicone, D., Ricci, S., Bastin, J. F, et al. (2016). Collect earth: Land use and land cover assessment through augmented visual interpretation. Remote Sensing, 8(10), 807. doi:10.3390/rs8100807.

8. Belay, T. (2002). Land use/land cover changes in the Derekolli catchment of the South Welo zone of Amhara region, Ethiopia, vol. XVII, no. 1. EASSRR; p. 20.

9. Brown, D. G. (2003). Land use and forest cover on private parcels in the Upper Midwest USA, 1970 to 1990. Landscape ecology, 18(8), 777-790.

10. Gerd, F., Brigitta, S. (2004). Watersherd Management - An Introduction, FWU, Vol.4, Lake Abaya Research Symposium-Proceedings.

11. Gete, Z. (2000). Landscape Dynamics and Soil Erosion Process Modeling in Thenorth-Western Ethiopian Highlands. PhD Thesis. Institute of Geography, University of Berne, Switzerland.

12. Grübler, A. (1994). Technology. In :Meyer, W.B., Turner, B.L. II (Eds.), Changes in Land Use and Land Cover :A Global Perspective. Univ. of Cambridge Press, Cambridge, pp. 287-328.

13. Heathcote, I. W. (1998). Integrated Watershed Management. Principles And Practice. New York.

14. Kiran V. S. S. (2013). Change Detection in Land use/Land cover Using Remote Sensing \& G.I.S Techniques: A Case Study of Mahanadi Catchment, West Bengal, International Journal of Research in Management Studies (IJRMS), 2(2).

15. Mustard, J. F., Defries, R. S., Fisher, T., Moran, E. (2005). Land use and land cover change pathways and impacts. In: Gutman G, Janetos AC, Justice CO,Moran EF,Mustard JF, Rindfuss RR, et al., editors. Land change science: observing, monitoring, and understanding trajectories of change on the earth's surface. Dordrecht, The Netherlands: Kluwer Academic Publishers. p. 411-29.

16. Open Foris (2016). Free Open-Source Solutions for Environmental Monitoring, (26.07.2018).

17. Reimold, R. J. (1998). Watershed Management. Practice, polices, and coordination. New York.

18. Solbrig, O. (1993). Ecological constraints to savanna land use. The World's Savannas: Economic driving forces, ecological constraints and policy options for sustainable land use. Man and the Biosphere Series, 12. UNESCO \& Parthenon Publ., Paris.

19. Symeonakis, E., Koukoulas, S. (2009). A Land use Change and Land Degradation Study in Spain and Greece Using Remote Sensing and GIS, J. Ind. Geophysics. Union, Vol.14, No.4, pp.180-190.

20. TUBITAK-MAM (2010). Havza Koruma Eylem Planlarının Hazırlanması Projesi, Konya Kapalı Havzası Nihai Raporu, (Proje yöneticisi: Dr. Selma AYAZ; Proje Kodu: 5098115), Kocaeli.

21. Tunçok, İ. K., Bozkurt, O. Ç. (2015). Bütüncül Havza Yönetimi: Konya Kapalı Havzası Uygulaması, 4. Su Yapıları Sempozyumu, 19-20 Kasım 2015. 
22. Turner, B. L., Skole, D., Sanderson, S., Fischer, G., Fresco, L., Leemans, R. (1995). Land Use Land Cover Change Science/Research Plan. Publications IHDP Report Series, Report Number 07. www.ihdp.unibonn.de/html/publications/report07/luccsp.htm.

23. Türkeş, M. (1999). Vulnerability of Turkey to desertification with respect to precipitation and aridity conditions. Turkish Journal of Engineering and Environmental Sciences, 23(5), 363-380.

24. URL-1 (2017). https://www.ipccggip.iges.or.jp/public/gpglulucf/gpglulucf_files/Chp2/Chp2_Land_Areas.pdf

25. URL-2 (2018). https://unfccc.int/cop7/documents/accords_draft.pdf

26. URL-3 (2018). https://www.ipcc.ch/meetings/session25/doc4a4b/vol4.pdf

27. URL-4 (2017). https://www.meteorite.bi/products/saiku

28. URL-6 (2018). http://www.cygm.gov.tr/CYGM/Files/Guncelbelgeler/HAVZA_FiNAL/Konya/Konya_ Kapali_Havzasi.pdf

29. WWF (2014). Konya'da Suyun Bugünü Raporu. Hazırlayanlar: Mustafa Özgür Berke, Buket Bahar Dıvrak, Hatice Dinç Sarısoy. WWF-Türkiye, Ofset yayınevi, 67 sayfa. 